\title{
Notes on the New Edition
}

When Campbell and Lynn Loughmiller published the first edition of Texas Wildflowers: A Field Guide in 1984, they gave a wonderful gift to anyone who traveled the highways and byways of Texas and admired the great diversity of natural beauty found along the way. The Loughmillers' clear love of Texas's flora shone forth both through their stunning photographs and through their homey, conversational descriptions of the species included in the pages of that first edition. My dog-eared copy of that edition is just as valuable to me today as it was then.

Sadly, in the years following the introduction of their field guide to Texas's wildflowers, we lost both Campbell and Lynn. But time moves forward, and by 2005 much had changed in our understanding of Texas's flora, especially in the area of nomenclature. In short, botanists had changed the names of many Texas wildflowers. Most of those changes were a result of our better understanding of the relationships between species.

Because of the Loughmillers' close connection to Lady Bird Johnson-her foreword was published in the first edition and has been included in each edition since-and to the Lady Bird Johnson Wildflower Center, to whom they donated their botanical image collection, the University of Texas Press turned to the Wildflower Center to edit a new edition. My former boss and mentor, Dr. Damon Waitt, took up the challenge and with skill and the lightest hand possible, brought the book up to date in 2008 . 
And still, time marches on.

By 2015 , botanical nomenclature continued to be in its perpetual state of flux, but also nature lovers were looking for different characteristics in their field guides. So the press asked me to take a swing at revising the book, this time with some structural changes. Somewhat naively perhaps, I accepted.

For those readers familiar with the earlier editions of this field guide, the changes you will find in these pages are not inconsequential. The biggest change is the overall organization of the book. The first two editions were organized by family, then by genus and species-the way most botanists would want a book organized. This edition is organized first by flower color, then by flowering time, and finally by genus and species. Our hope is that this new organizational scheme will make the book more useful to novice wildflower enthusiasts by making the identity of their mystery flower easier to find. For those who prefer to search for plants by family name, a family name index is provided in the back of the book.

In moving away from the family-based organization, by necessity we lost the excellent family discussions written by the Loughmillers. I have tried to incorporate as much of that information as possible into the species descriptions in the pages of this book.

This edition also introduces a more formal organizational style for the species descriptions. Each page includes sections for "Plant and Leaves," "Flowers and Fruit," "Flowering," "Range and Habitat," and finally, "Comments." Many of the comments are excerpted from the Loughmillers' original work. Our hope is that this new format will make the information the reader is seeking easier to find.

When travelers find an unknown wildflower on a roadside or along a trail, they typically ask themselves two questions: "What plant is that?" and "What is its story?" Early in their travels, the Loughmillers surely asked themselves those very questions, and ultimately the results of their investigations were shared with the world in the pages of that first edition of this field guide.

It is my fondest hope that within the pages of this edition you will find the answer to that first question for some of your unknown Texas wildflowers and will find enough of those plants' 
stories to lead to a deeper and richer understanding and appreciation of Texas's remarkable native flora.

I would like to thank the Lady Bird Johnson Wildflower Center for allowing me to work on this project. Also, I am indebted to the many wonderful wildflower photographers who have graciously contributed their work to the Wildflower Center's Native Plant Information Network Image Gallery and have allowed us to also publish them in this field guide. Finally, I wish to give the most heartfelt thank you to Annelia Williams, whose numerous suggestions and excellent organizational skills provided much invaluable assistance in the development of this new edition.

JOE MARCUS

Lady Bird Johnson Wildflower Center 